\title{
Separation of Alkane Isomers by Exploiting Entropy Effects during Adsorption on Silicalite-1: A Configurational-Bias Monte Carlo Simulation Study
}

\author{
M. Schenk, S. L. Vidal, T. J . H. Vlugt, B. Smit, and R. Krishna* \\ Department of Chemical Enginering, University of Amsterdam, Nieuwe Achtergracht 166, \\ 1018 WV Amsterdam, The Netherlands
}

Received August 18, 2000. In Final Form: November 29, 2000

\begin{abstract}
We discuss and develop an entropy-driven principlefor separating isomers of alkanes in thefivetoseven carbon atom range by adsorption on silicalite-1. The normal alkanes are preferentially adsorbed because of configurational entropy effects; they "pack" more efficiently within the channel structures of silicalite. To demonstrate the separation principle we carried out CBMC simulations to determine the isotherms of various mixtures of linear and branched alkanes in silicalite-1. Weshow that the configurational entropy effects manifest at loadings greater than 4 molecules/unit cell and the sorption favors the linear alkanes while the branched alkanes are virtually excluded from the silicalite matrix. Validation of the entropybased separation principle is obtained by analyzing the silicalite membrane permeation data published in the literature.
\end{abstract}

\section{Introduction}

The separation of isomers of alkanes is a problem that is growing in industrial importance. New reformulated gasoline specifications are forcing petroleum refiners to reduce the amount of olefins and aromatics in gasoline, and consequently, there is a greater need in the refining industry for catalyticisomerization for convertingstraight chain hydrocarbons to branched hydrocarbons. Branched hydrocarbons arepreferred tostraight-chain hydrocarbons as ingredients in gasol inebecause branched hydrocarbons burn more efficiently and have a higher octane number. Consider, for example, the isomers of hexane; n-hexane has a RON (research octane number) $=30$ whereas the corresponding RON values for its isomers are the following: 2-methylpentane (2MP), 74.5; 3-methylpentane (3MP), 75.5; 2,2-dimethylbutane (22DMB), 94; 2,3-dimethylbutane(23DMB), 105. I n thecatalyticisomerization process, straight-chain hydrocarbons areconverted totheir mono- or dibranched structures. However, the product of catalyticisomerization is a mixture of linear and branched hydrocarbons that arein thermodynamic equilibrium and theseparation of linear hydrocarbons from their branched isomers becomes necessary. The separation of the hydrocarbon isomers is usually carried out using adsor ption in a bed of zeolite 5A particles ${ }^{1,2}$ in which the principle of separation is that of molecular sieving. Only the linear paraffin is capable of entering the pores of 5A zeol ite, and the branched isomers are excluded. One important disadvantage of sorption separation using 5A zeolite is that the diffusivities, and hence the fluxes, are very low. Therefore equipment sizes are large.

Our research focus is the separation of alkane isomers by expl oiting subtleentropy effects. A careful examination of thephysical properties of linear and branched alkanes ${ }^{3}$ shows that the largest difference between the properties

* Correspondingauthor.Fax: +31205255604.E-mail: krishna@ its.chem.uva.nl.

(1) Kärger, J .; Ruthven, D. M. Diffusion in zeolites and other microporous solids; Wiley: New York, 1992.

(2) Ruthven, D. M.; Faroog, S.; Knaebel, K. S. Pressure Swing Adsorption; VCH Publishers: New York, 1994.

(3) Reid, R. C.; Prausnitz, J . M.; Poling, B. M. Theproperties of gases and liquids, 4th ed.; McGraw-Hill: New York, 1988; pp 656-657. of alkanes isomers is with respect to the freezing point. When a mixture of, for example, $\mathrm{nC}_{6}$ and $2 \mathrm{MP}$ is cooled, the first crystals to form will be that of the linear isomer. The reason is that the linear paraffin molecules "stack" more easily. Branching destroys the symmetry required for crystal formation. In other words the differences in the freezing points is due to differences in "ordering" or "packing" efficiencies. The major drawback in applying this princi ple to separatelinear and branched al kanes in the gasoline boiling range is that the temperatures to which the mixtures must be cooled is very low, of the order of $120-180 \mathrm{~K}$. Therefore freeze crystallization is not a viabletechnol ogical solution for separation of isomers in the 4-7 C atom range. I deally we would like to be able to exploit packing efficiency, or configurational entropy, differences without the need to cool to such low temperatures required for crystallization. To achieve this goal we consider adsorption of the alkane isomers inside the matrix of an ordered structure, such as that of silicalite-1. Silical iteconsists of straight channels and zigzagchannels, which cross each other at intersections. The length of the normal hexane molecule, for example, is commensurate with the length of the zigzag channel, between two intersections. ${ }^{4}$ That the linear molecules pack more efficiently within thesilicalitestructure is al so evidenced by the differences in the saturation loadings, expressed in molecules/unit cell, between linear and branched alkanes in silical ite; see F igure 1 . We aim to demonstrate in this paper that, for mixtures of linear and branched alkanes, such differences in "packing" efficiencies could cause an almost total exclusion of the branched isomer.

Todemonstrateour entropy-driven sorption separation of alkane isomers using medium pore-size silicalite, we need to be abl e to estimate the sorption characteristics of various mixtures of linear and branched alkanes in the 5-7 carbon atom range, of interest as components in gasol ine. Whilethereis a considerableamount of published experimental data on pure component isotherms for various alkanes and isoalkanes, ${ }^{5-9}$ there is little or no experimental data on mixture isotherms. This lack of mixture isotherm data is most probably due to the

(4) Smit, B.; Maesen, T. L. M. Nature 1995, 374, 42. 


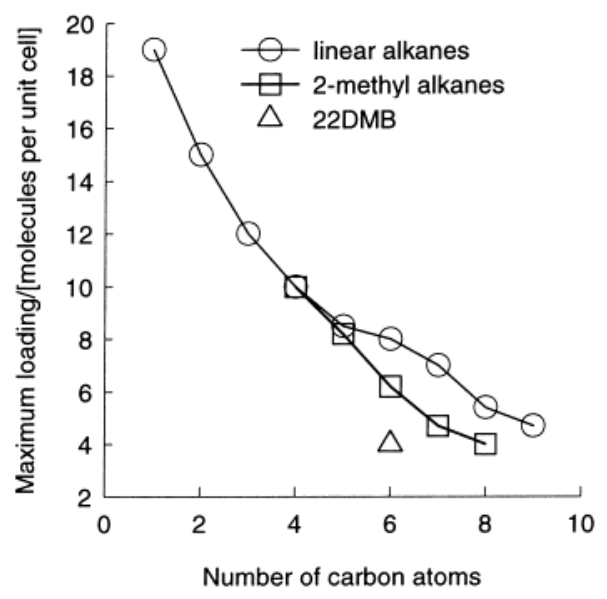

Figure 1. Saturation loadings (molecules/unit cell) of alkanes in silicalite-1 obtained from CBMC simulations at $\mathrm{T}=300 \mathrm{~K}$.

difficulty of experimentation. In this paper we discuss a strategy for generating the required mixture isotherms using configurational-bias M onte Carlo (CBMC) simulations. The study reported here is not only of technol ogical importance in the context of isomer separation but emphasizes some new scientific principles governing sorption of molecules in confined environments such as zeolites and other nanoporous materials.

There are several factors which determine the sorption behavior of mixtures: (1) There are differences in chain lengths (i.e. number of carbon atoms) of the components. In general, the longer the chain length, the higher is the adsorption strength. This is illustrated in Figure 2 which shows the sorption isotherms of (a) linear al kanes and (b) branched alkanes in silicalite at T $=300 \mathrm{~K}$. (2) Another factor is the inflection behavior of the components. All branched alkanes show inflection behavior at a loading of 4 molecules/unit cell. Linear alkanes show pronounced inflection behavior for $\mathrm{C}$ atoms exceeding 6 . Inflection behavior is caused by configurational effects, causing preferential siting of molecules at certain positions in silicalite. Inter esting effects, such as selectivity reversal and exclusion of the branched alkane, can be expected to arise when one of the components in the mixture exhibits inflection behavior; this is often the case for a mixture of linear and branched alkanes. ${ }^{10}$ (3) A final factor is differences in maximum molecular loadings of the components. The maximum loadings for linear and 2-methyl alkanes are shown in Figure 1 as a function of thenumber of $\mathrm{C}$ atoms; the maximum loading decreases with increasing $C$ number. This is a size entropy effect. For example, for a mixture of methaneand propane, sizeentropy effects tends tofavor methaneat high loadings. ${ }^{11,12}$ This is because the smaller methane mol ecule finds it easier to fill in the "gaps" at high loadings within the zeolite.

It is worthwhile describing the overall structure and strategy to be adopted in this paper to give some

(5) Boulicaut, L.; Brandani, S.; Ruthven, D. M. Microporous Mesoporous Mater. 1998, 25, 81.

(6) Caval cante, C. L., J r.; Ruthven, D. M. Ind. Eng. Chem. Res. 1995 35, 177.

(7) Millot, B.; Methivier, A.; J obic H. Paper presented at the 6th International Conference on Fundamentals of Adsorption, May 24-28, 1998; pp 273-278.

(8) Sun, M. S.; Talu, O.; Shah, D. B.J . Phys. Chem. 1996, 100, 17276

(9) Zhu, W.; Kapteijn, F.; Moulijn, J. A. Phys. Chem. Chem. Phys. 2000, 2, 1989.

(10) Krishna, R.; Smit, B.; Vlugt, T.J . H.J . Phys. Chem. A 1998, 102, 7727.

(11) Krishna, R.; Paschek, D. Sep. Purif. Technol. 2000, 21, 111.

(12) Kapteijn, F.; Moulijn, J . A.; Krishna, R. Chem. Eng. Sci. 2000, 55, 2923.
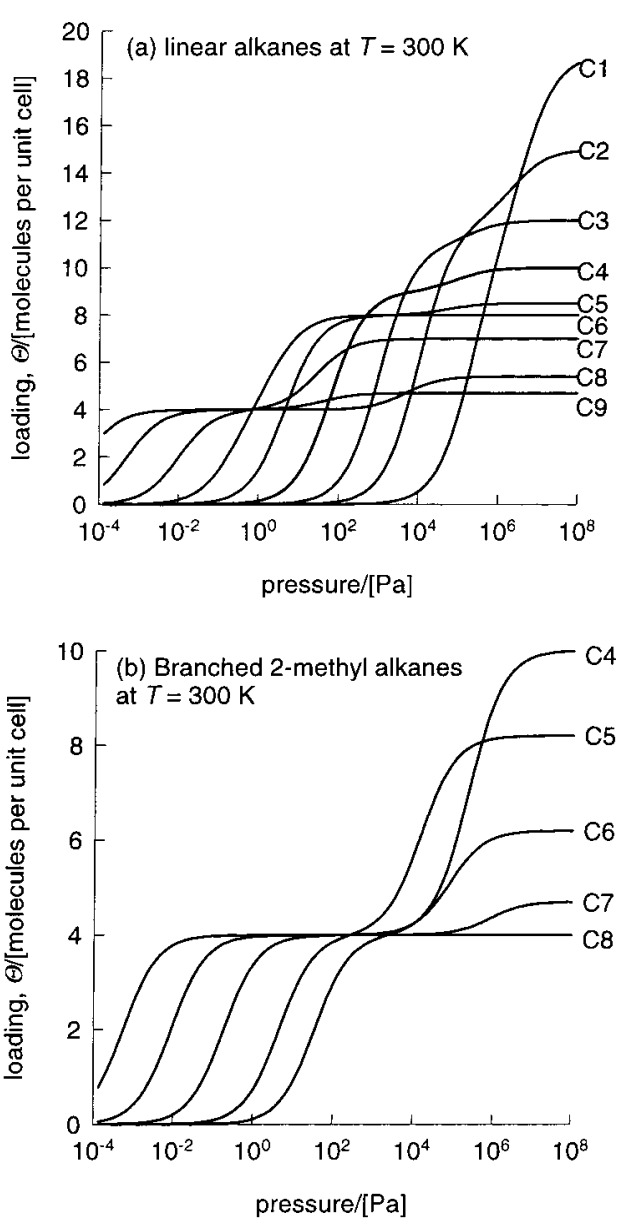

Figure 2. Pure component isotherms for (a) linear and (b) 2-methylalkanes in silicalite-1 at $300 \mathrm{~K}$ cal culated using CBMC.

perspective to the individual sections. First, we describe the details of the CBMC technique. Then pure component isotherms aresimulated and compared with experimental data to demonstrate the accuracy of CBMC simulations. Subsequently, the entropy-driven separation principle is demonstrated by carrying out mixture simulations for isomers. We seek verification of the entropy separation principle by analyzing published silicalite membrane permeation data of Funke et al. ${ }^{13}$ and Gump et al. ${ }^{14}$ Subsequently, we examine mixtures of linear and branched alkanes where the constituents have different number of carbon atoms.

It is important to remark here that we had first introduced the entropy-driven separation concept in an earlier short communication; ${ }^{10}$ the current article represents a fuller account of this concept and demonstrates its generic character. Furthermore, since the publication of our short communication, new experimental data on permeation of alkaneisomers across a silical itemembrane have been publ ished by Gump et al. ${ }^{14}$ Torationalizetheir experimental data, we performed many moresimulations with various mixtures under a variety of temperature, pressures and compositions. Our simulations offer a fundamental explanation of their experimental results which is different from that presented by Gump et al. ${ }^{14}$ Thegenericcharacter of our approach is al so demonstrated by considering the sorption of isomers of decane on two types of zeolitic structures: silicalite and MEL.

(13) Funke, H. H.; Argo, A. M.; Falconer, J . L.; Noble, R. M. Ind. Eng. Chem. Res. 1997, 36, 137.

(14) Gump, C. J .; Noble, R. D.; Falconer, J . L. Ind. Eng. Chem. Res. 1999, 38, 2775. 


\section{Configurational-Bias Monte Carlo (CBMC) Simulation Technique}

The linear and branched alkanes are described with a united-atom model, in which $\mathrm{CH}_{3}, \mathrm{CH}_{2}$, and $\mathrm{CH}$ groups are consi dered as single interaction centers. When these pseudoatoms bel ong to different molecules or to the same molecule but separated by more than three bonds, the interaction is given by a Lennard-J ones potential. The Lennard-J ones parameters are chosen to reproduce the vapor-liquid curve of the phase diagram as shown in Siepmann et al. ${ }^{15}$ The bonded interactions include bondbending and torsion potentials. Details for the alkane model can be found in Vlugt et al. ${ }^{16}$

All the simulations have been performed in zeolite silicalite (MFI). Silicalite has both straight elliptical channels and zigzag channels that cross at the intersections. Following Kiselev and co-workers, ${ }^{17}$ we consider the zeolite lattice to be rigid and we assume that interactions of an alkane with the zeolite are dominated by the dispersiveforces between alkanepseudoatoms and the oxygen atoms of the zeolite. These interactions are described by a Lennard-J ones potential, which parameters are given in ref 16 .

Adsorption isotherms are conveniently computed using a Monte Carlo simulation in the grand-canonical ensemble. ${ }^{18}$ In this ensemble the temperature and chemical potentials areimposed. Thenumber of adsorbed molecules per unit cell of the zeolite follows from the simulations. The characteristics of these type of simulations is that during the calculations attempts are made to change the total number of particles by making attempts to insert molecule into or remove molecules from the zeolite. To make these types of moves possible for the long chain alkanes, we use the configurational-bias Monte Carlo (CBMC) technique. ${ }^{18,19}$ I nstead of inserting a molecule at a random position, in a CBMC simulation a molecule is grown atom by atom in such a way that the "empty spots" in the zeolite are found. This growing scheme gives a bias that is removed exactly by adjusting the acceptance rules. ${ }^{18,19}$

Thesesimulations were performed in cycles, and in each cycle, an attempt to perform one of the following moves was made: (1) Displacement of a randomly selected chain was attempted. Themaximum displacement was adjusted to an overall acceptance of $50 \%$. (2) Rotation of a chain around its center of mass was attempted. The chain is chosen at random and the maximum rotation angle is selected to accept $50 \%$ of the moves. (3) Partly regrowing of a chain was tried; a chain is selected at random and part of the molecule is regrown using the CBMC scheme. It is decided at random which part of the chain is regrown and with which segment the regrowing is started. For branched alkanes, theapproach in Vlugt et al. ${ }^{16}$ was used. (4) Regrowing of the entire chain (only for NVT simulations) was attempted. A chain selected at random is completely regrown at a random position. (5) Exchange with a reservoir (only in grand-canonical simulations) was tried. It is decided at random whether to add or to remove a mol ecule from thezeol ite following the acceptance rules

(15) Siepmann, J . I.; Martin, M. G.; Mundy, C. J .; Klein, M. L. Mol . Phys. 1997, 90, 687.

(16) Vlugt, T.J . H.; Krishna, R.; Smit, B.J .Phys. Chem. B 1999, 103, 1102.

(17) Bezus, A. G.; Kiselev, A. V.; Lopatkin, A. A.; Du, P. Q. J . Chem. Soc., Faraday Trans. 2 1978, 74, 367.

(18) Frenkel, D.; Smit, B. Understandingmolecular simulations: from algorithms to applications; Academic Press: San Diego, CA, 1996.

(19) Frenkel, D.; Mooij, G. C. A. M.; Smit, B. J . Phys.: Condens Matter 1992, 4, 3053. derived in Vlugt et al. ${ }^{16}$ and Smit. ${ }^{20}$ (6) Finally, a change of identity (only in the case of mixtures) was tried; one of the components is selected at random and an attempt is madeto changeits identity (Martin and Siepmann ${ }^{21}$ ). The acceptance rules for these trial moves can be found in Frenkel and Smit ${ }^{18}$ and Smit. ${ }^{20}$

For the pure components adsorption isotherm, $2 \times 10^{5}$ Monte Carlo cycles were performed, and for the mixture adsorption isotherms, the number of cycles was $3 \times 10^{7}$. Therelativeprobabilities for attempting these moves were such that in theNVT simulations $10 \%$ of the total number of moves were displacements, $10 \%$ rotati ons, $10 \%$ partial regrowths, and $70 \%$ regrowths of the entire molecule. F or the case of grand-canonical simulations of the pure components the relative probabilities of moves were the following: $15 \%$ displacements; $15 \%$ rotations; $15 \%$ partial regrowths; $55 \%$ exchanges with the reservoir. For the mixture the number of exchanges was reduced to $50 \%$ and the remaining $5 \%$ of the moves were attempts to change the identity of a molecule. The number of trial orientations in the configurational-bias Monte Carlo scheme was six for all molecul es. In addition, we used the multiplefirst bead scheme ${ }^{22}$ with 15 trial positions for the first bead.

\section{CBMC Simulation Results for Pure Components and Mixtures}

Pure Component Isotherms of Hexane Isomers. We first consider the isomers $\mathrm{n}$-hexane $\left(\mathrm{nC}_{6}\right), 2$-methylpentane (2MP), 3-methylpentane (3MP), and 2,2-dimethyl butane (22DMB). The pure component isotherms at various temperatures are shown in Figure $3 a-d$. A good description of the pure component isotherms can be obtained with the dual-site Langmuir (DSL) model. ${ }^{11} \mathrm{In}$ this model the loading, $\Theta_{i}{ }^{0}(P)$, expressed in molecules/ unit cell, is represented as a function of the pressure $P$ as follows:

$$
\Theta_{i}{ }^{0}(P)=\frac{\Theta_{i, s a t, A} b_{i, A} P}{1+b_{i, A} P}+\frac{\Theta_{i, \text { sat }, B} b_{i, B} P}{1+b_{i, B} P}
$$

The superscript 0 on $\Theta^{0} \mathrm{i}(\mathrm{P})$ is used to emphasize that the relation is for pure component loadings. In eq $1 b_{1, A}$ and $b_{1, B}$ represent the DSL model parameters expressed in $\mathrm{Pa}^{-1}$ and the subscripts $\mathrm{A}$ and $\mathrm{B}$ refer to two sorption sites within the silicalite structure, with different sorption capacities and sorption strengths. $\Theta_{i \text {,sat. }}$ and $\Theta$ i.sat. represent the saturation capacities of sites $A$ and $B$, respectively. Thefitted parameters for thepurecomponent isotherms are listed in Table 1 . It is to be noted that the total saturation loading $\Theta_{i, \text { sat }}=\Theta_{i, \text { sat, } A}+\Theta_{i, \text { sat }, \mathrm{B}}$ is not a fitted parameter but taken from the final plateau value of the sorption isotherm, estimated from CBMC simulations. Figure 3 also shows the fitted DSL model. It is to be observed that nC 6 shows a slight inflection at $\Theta=4$ due to commensurate freezing. ${ }^{4}$ The branched isomers $2 \mathrm{MP}$ and $3 \mathrm{MP}$ also show an inflection at $\Theta=4$ for some temperatures because these molecules prefer the intersections between the straight and zigzag channels of silicalite; to push them intothe channel interiors requires an extra "push", leading toinflection behavior. Theisomer 22DMB is so bulky that it can be located only at the

(20) Smit, B. Mol. Phys. 1995, 85, 153

(21) Martin, M. G.; Siepmann, J . I. J . Am. Chem. Soc. 1997, 119, 8921. 1560 
(a) n-hexane isotherms

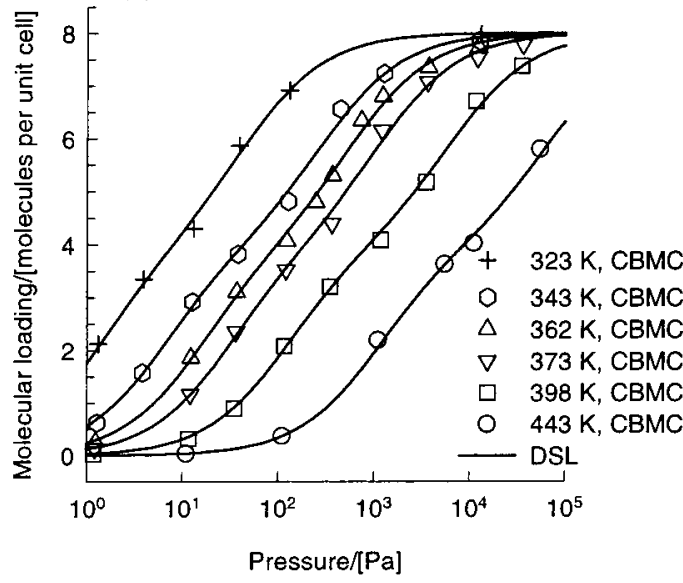

(b) 2MP isotherms

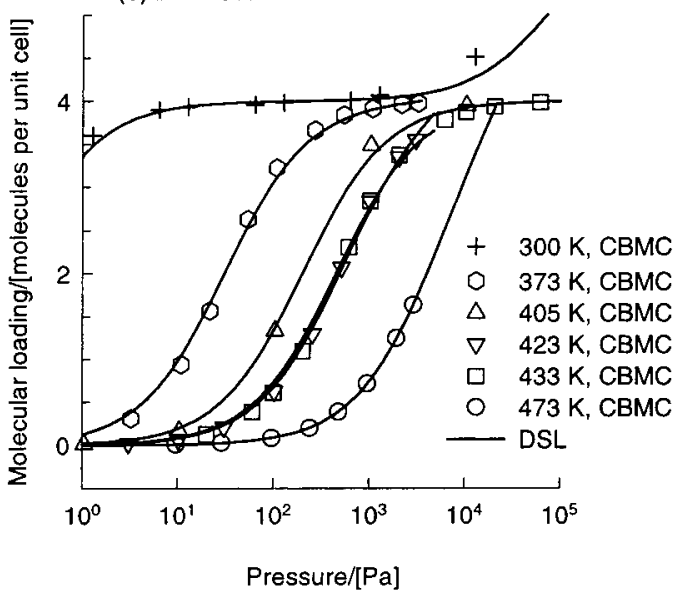

(b) 22DMB isotherms

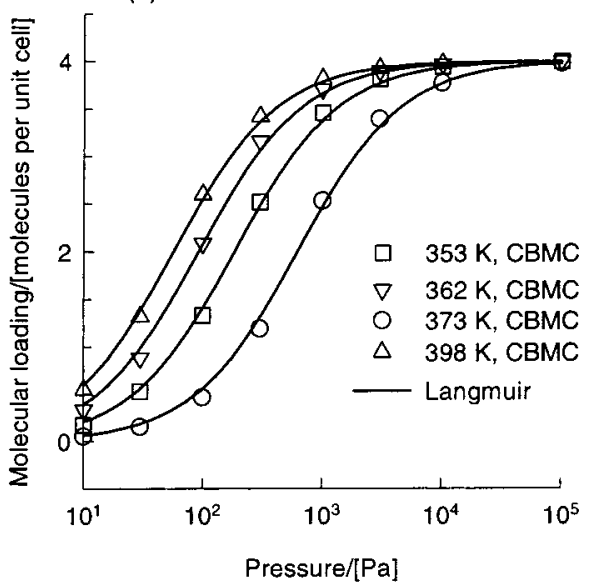

(b) 3MP isotherms

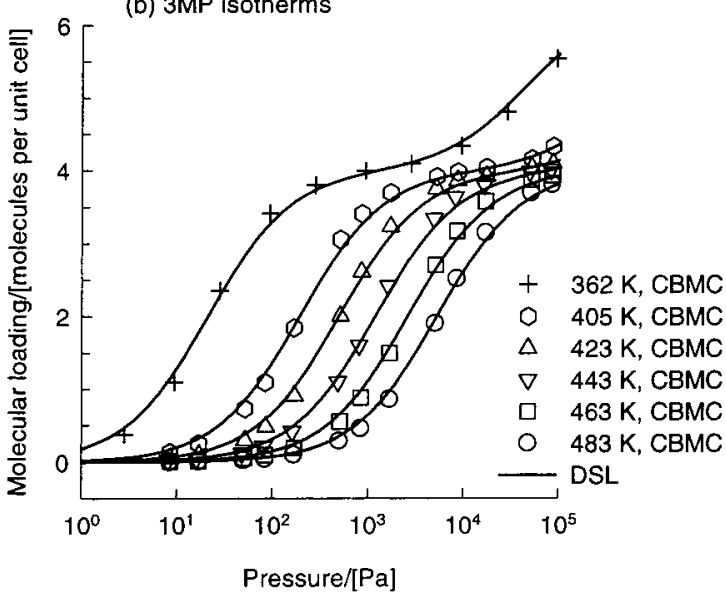

Figure 3. Pure component isotherms of hexane isomers obtained at various temperatures using CBMC simulations.

Table 1. Pure Component Sorption Parameters for Dual-Site Langmuir Model Applied to Silicalite

\begin{tabular}{|c|c|c|c|c|c|}
\hline \multirow[b]{3}{*}{ component } & \multirow[b]{3}{*}{$\underset{\mathrm{K}}{\text { temp/ }}$} & \multicolumn{4}{|c|}{ dual-site Langmuir params (eq 1) } \\
\hline & & \multicolumn{2}{|c|}{ site $A$} & \multicolumn{2}{|c|}{ site $B$} \\
\hline & & $\mathrm{b}_{\mathrm{i}, \mathrm{A}} / \mathrm{Pa}^{-1}$ & $\begin{array}{c}\Theta_{\mathrm{i}, \mathrm{sat}, \mathrm{A}} / \\
\text { molecules } \\
\text { per unit cell }\end{array}$ & $\mathrm{b}_{\mathrm{i}, \mathrm{B}} / \mathrm{Pa}^{-1}$ & $\begin{array}{c}\Theta_{\mathrm{i}, \text { sat, }} / \\
\text { molecules } \\
\text { per unit cell }\end{array}$ \\
\hline \multirow[t]{2}{*}{$\mathrm{nC5}$} & 310 & 0.25 & 4 & 0.06 & 4 \\
\hline & 433 & $2.43 \times 10^{-4}$ & 4 & $3.24 \times 10^{-5}$ & 4 \\
\hline \multirow[t]{9}{*}{$\mathrm{nC6}$} & 300 & 4.62 & 4 & 0.422 & 4 \\
\hline & 323 & 0.73 & 4 & $2.2 \times 10^{-2}$ & 4 \\
\hline & 343 & 0.158 & 4 & $3.4 \times 10^{-3}$ & 4 \\
\hline & 353 & 0.12 & 4 & $3.5 \times 10^{-3}$ & 4 \\
\hline & 362 & $6.32 \times 10^{-2}$ & 4 & $1.7 \times 10^{-3}$ & 4 \\
\hline & 373 & $3.21 \times 10^{-2}$ & 4 & $8.8 \times 10^{-4}$ & 4 \\
\hline & 398 & $8.24 \times 10^{-3}$ & 4 & $1.56 \times 10^{-5}$ & 4 \\
\hline & 433 & $1.44 \times 10^{-3}$ & 4 & $2.16 \times 10^{-5}$ & 4 \\
\hline & 443 & $8.9 \times 10^{-4}$ & 4 & $1.44 \times 10^{-5}$ & 4 \\
\hline $2 \mathrm{MB}$ & 310 & 0.25 & 4 & $1 \times 10^{-4}$ & 4 \\
\hline $2 \mathrm{MP}$ & 433 & $2.17 \times 10^{-3}$ & 4 & & \\
\hline \multirow[t]{6}{*}{ 3MP } & 362 & $4.75 \times 10^{-2}$ & 4 & $2.27 \times 10^{-5}$ & 2.3 \\
\hline & 403 & $5.2 \times 10^{-3}$ & 4 & $1.9 \times 10^{-6}$ & 2.3 \\
\hline & 423 & $2.02 \times 10^{-3}$ & 4 & $7.14 \times 10^{-7}$ & 2.3 \\
\hline & 443 & $8.45 \times 10^{-4}$ & 4 & $3.4 \times 10^{-7}$ & 2.3 \\
\hline & 463 & $3.85 \times 10^{-4}$ & 4 & $1.18 \times 10^{-7}$ & 2.3 \\
\hline & 483 & $1.91 \times 10^{-4}$ & 4 & $6.41 \times 10^{-8}$ & 2.3 \\
\hline \multirow[t]{3}{*}{ 22DMB } & 362 & 0.011 & 4 & & \\
\hline & 373 & $5.43 \times 10^{-3}$ & 4 & & \\
\hline & 398 & $1.75 \times 10^{-3}$ & 4 & & \\
\hline $\mathrm{nC7}$ & 374 & 0.15 & 4 & $3 \times 10^{-5}$ & 2.9 \\
\hline \multirow[t]{2}{*}{$2 \mathrm{MH}$} & 374 & 0.17 & 4 & $2 \times 10^{-9}$ & 0.7 \\
\hline & 433 & 0.01 & 4 & & \\
\hline
\end{tabular}

inter sections; there is no inflection for this component for the range of temperatures and pressures studied.
To verify the accuracy of our CBMC technique, we compared the CBMC simulation results for pure component isotherms with the experimental measurements of Caval cante and Ruthven 6 and Millot et al.; ${ }^{7}$ see Figure 4. The agreement between CBMC simulations and experimental data fits of these authors can be considered to be good for a wide range of pressures and temperatures.

Pure Component Permeation Selectivities across Silicalite Membrane. Further verification of the pure component CBMC simulations will now be obtained by examining experimental results on permeation of pure components across a silicalite membrane. Funke et al. ${ }^{13}$ have presented data on the ratio of permeation fluxes of (1) nC6 and (2) 3MP at 362 and $405 \mathrm{~K}$, keeping the upstream hydrocarbon pressures at $15 \mathrm{kPa}$; see Table 3 of their paper. They observed the $\mathrm{nC}_{6} / 3 \mathrm{MP}$ permeation selectivities to be 1.3 and 1.9, respectively. Let us first try torationalizetheseexperimental findings. Thepermeation flux of component 1, e.g., is expected to be proportional to the Fick diffusivity, $\mathrm{D}_{1}$, inside the zeolite matrix and thedriving force for transport across themembrane, $\Delta \Theta_{1}$, which is the difference between the molecular loadings in the upstream and downstream faces of the membrane. In their membrane experiments the downstreammembrane compartment is purged with inert gas, keeping the partial pressures to near zero values. Therefore the driving force $\Delta \Theta_{1}$ can be taken to be the loading corresponding to the upstream pressureconditions, i.e., $\Delta \Theta_{1}=\Theta_{1}$ corresponding to $p_{1}$. Theflux of any component is ther efore proportional to the diffusivity of that component and its molecular loading at theupstream pressureconditions. Thesorption 
(a) n-hexane: CBMC vs Expts

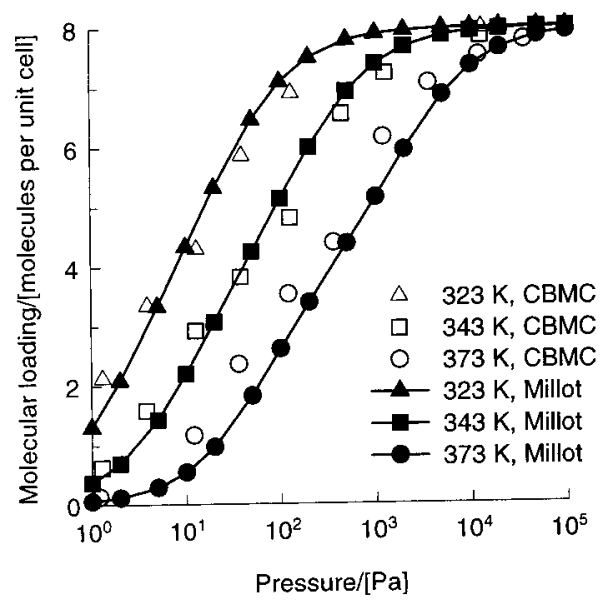

(c) 2MP: CBMC vs Expts

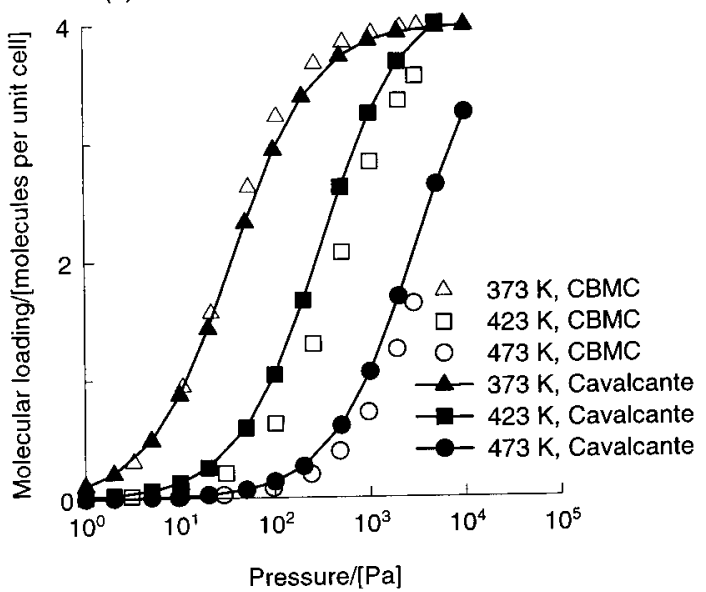

(b) 22DMB: CBMC vs Expts

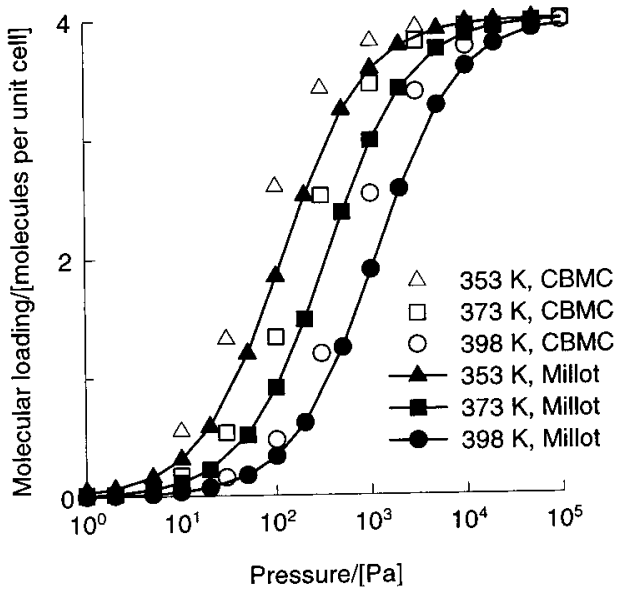

(d) 3MP: CBMC vs Expts

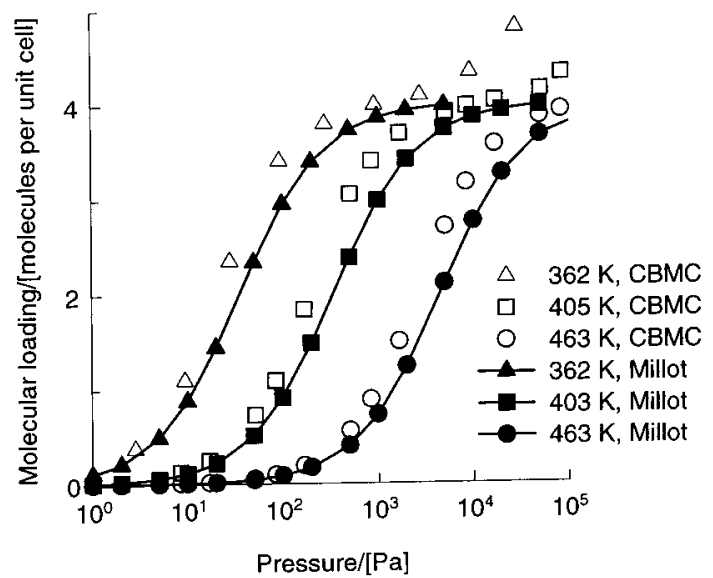

Figure 4. Comparison of experimental data with CBMC simulations for pure component isotherms of hexane isomers obtained at various temperatures.

isotherm is therefore an important determinant in the permeation behavior across a membrane. From the experimental data on thepurecomponent permeations in two separate experiments, the permeation selectivity $S_{p}$ can be calculated as follows:

$$
S_{P}=\frac{D_{1}}{D_{2}} \frac{\Theta_{1}}{\Theta_{2}} \frac{p_{2}}{p_{1}}
$$

In Figure 5 a the measured values of $S_{p}$ are compared with the sorption selectivity $\mathrm{S}$

$$
\mathrm{S}=\frac{\Theta_{1}}{\Theta_{2}} \frac{p_{2}}{p_{1}}
$$

determined from CBMC simulations. The values of $S_{p}$ and $S$ are quite close to one another, suggesting that the ratio of Fick diffusivities $D_{1} / D_{2}$ of thelinear and branched isomers, $\mathrm{nC}_{6}$ and $3 \mathrm{MP}$, is close to unity. It is noteworthy that the ratio of pure Fick diffusivities measured by Caval canteand Ruthven ${ }^{6}$ for $\mathrm{nC} 6$ and $3 \mathrm{MP}$ is much higher than unity. The precise reasons behind this discrepancy is not known. It appears that to interpret membrane permeation data one must measure the pure component Fick diffusivities using the same membrane and not rely on single-crystal or chromatographic studies for this information.

Gump et al. ${ }^{14}$ have presented experimental results for thepermeation fluxes of purecomponents $\mathrm{nC}_{6}$ and $22 \mathrm{DM} \mathrm{B}$ across a silicalite membrane at $353 \mathrm{~K}$ and at various upstream pressures; see Figure 4 of their paper. We calculated the permeation selectivities $S_{p}$ for these experiments and compared them with the sorption selectivities $\mathrm{S}$ using the pure component CBMC simulations at $353 \mathrm{~K}$; the compari son between $S_{p}$ and $S$ is shown in Figure $5 \mathrm{~b}$. We again note the close agreement between the permeation and sorption selectivities. The values of $\mathrm{S}_{\mathrm{p}}$ are consistently higher than that of $\mathrm{S}$ suggesting that the ratio of Fick diffusivities $D_{1} / D_{2}$ of the linear and branched i somers, $\mathrm{nC}_{6}$ and 22DM B, is only slightly higher than unity. It is again to be noted that the ratio of pure Fick diffusivities of $\mathrm{nC}_{6}$ and 22DMB measured by Boulicaut et al. ${ }^{5}$ is a few orders of magnitude higher than unity and the reasons behind this discrepancy remain unclear.

Funke et al. ${ }^{13}$ al so published experimental results for the permeation fluxes of pure components $3 \mathrm{MP}$ and 22DMB across a silicalite membrane at $362 \mathrm{~K}$ keeping the upstream hydrocarbon pressure at $12 \mathrm{kPa}$; see Table 5 of their paper. Wecalculated the permeation selectivities $S_{p}$ for this experiment and compared them with the sorption selectivities S using the pure component CBMC simulations at $362 \mathrm{~K}$; the comparison between $S_{p}$ and $S$ is shown in Figure $5 c$. Once again we note the close agreement between the permeation and sorption selectivities.

The results of Figure 5 allow us to conclude that the CBMC simulations can beused with confidenceto estimate 
(a) $\mathrm{n}-\mathrm{C} 6 / 3 \mathrm{MP}$ selectivity; $P=15.12 \mathrm{kPa}$
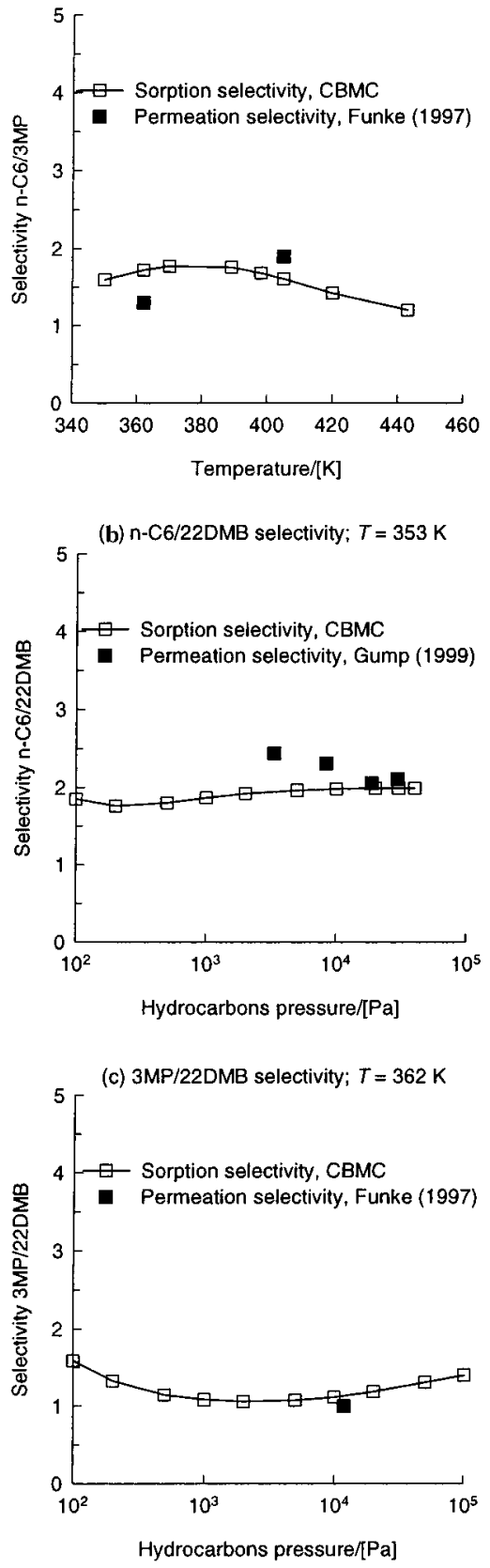

Figure 5. Comparison of experimental data with CBMC simulations for sor ption selectivities based on pure component data.

the pure component permeation selectivities of hexane isomers across a silicalite membrane.

Sorption of $n$-Hexane-3-Methyl pentaneMixtures. Let us now consider sorption of a 50-50 mixture of $\mathrm{nC}_{6}$ and 3MP at temperatures of 362 and $443 \mathrm{~K}$. CBMC simulations for the loadings in the mixture as shown in Figure $6 a, b$ for a range of pressures. It is interesting to note the maximum in the loading of $3 \mathrm{MP}$ at about $100 \mathrm{~Pa}$ for $362 \mathrm{~K}$ and at about $10000 \mathrm{~Pa}$ at $443 \mathrm{~K}$. When the pressure is raised above these pressures, the loading of $3 \mathrm{MP}$ reduces virtually tozero. Then $\mathrm{C}_{6}$ molecules fit nicely into both straight and zigzag channel ${ }^{16}$ whereas the $3 \mathrm{MP}$ molecules are preferentially located at the intersections between the straight channels and the zigzag channels; see Figure 7. The $\mathrm{nC}_{6}$ molecules have a higher packing efficiency within the silicalite matrix than the 3MP molecules. It is more efficient to obtain higher loading by (a) $362 \mathrm{~K}$

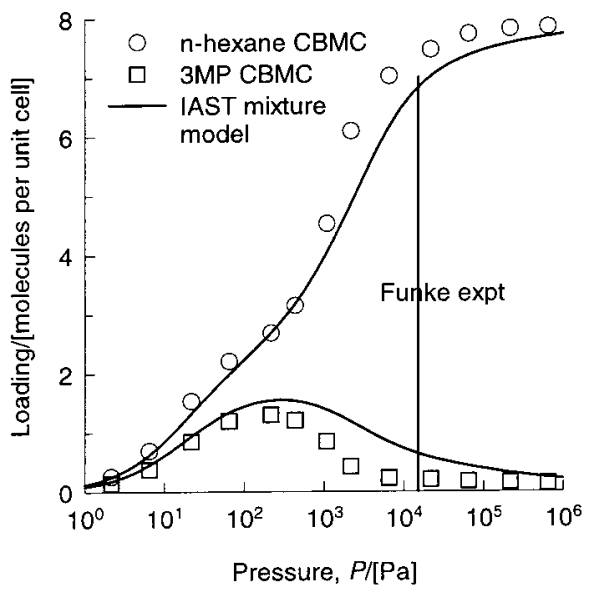

(b) $443 \mathrm{~K}$

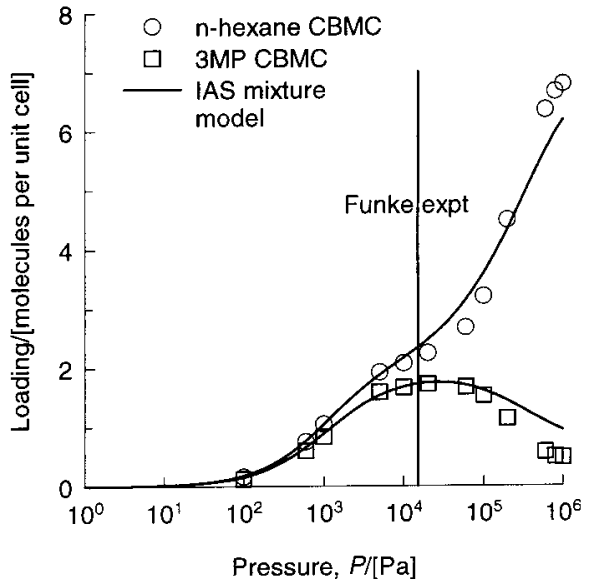

Figure 6. $C B M C$ simulations for $50-50$ mixture isotherm for nC6-3MP at 362 and $443 \mathrm{~K}$.

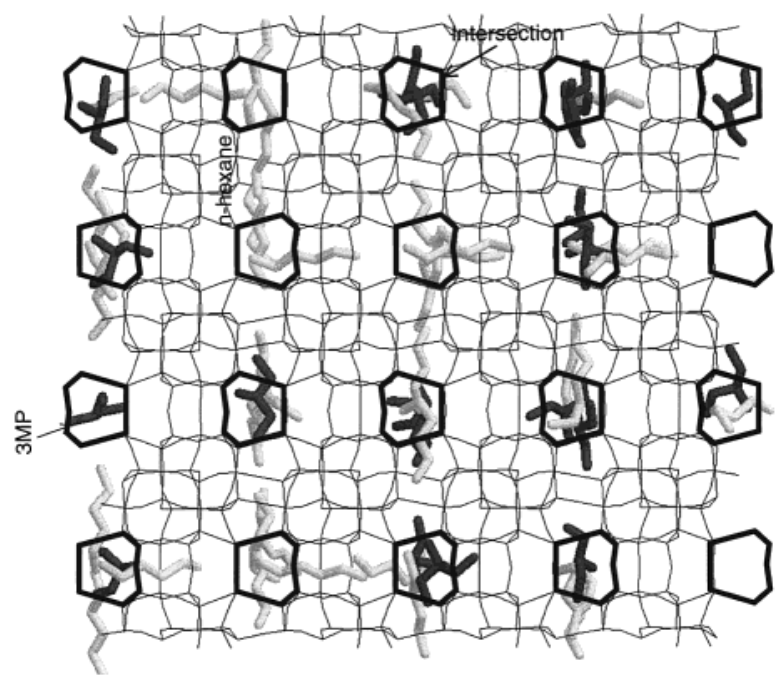

Figure 7. Typical snapshot showing the location of a 50-50 mixture of n-hexane (1)-3MP (2) at $362 \mathrm{~K}$ and $100 \mathrm{~Pa}$. Preferential siting of $3 \mathrm{MP}$ alkanes at theintersections between the straight and zigzag channels is evident. The linear al kane can be located at any position within the silicalite structure.

"replacing"the $3 \mathrm{MP}$ with $\mathrm{nC}_{6}$; this configurational entropy effect is the reason behind the curious maxima in the 3MP loading in the mixture.

Before seeking experimental verification of the curious mixture behavior, let us try to estimate the mixture 
(a) $\mathrm{nC6} / 3 \mathrm{MP}$ selectivity at $362 \mathrm{~K}$

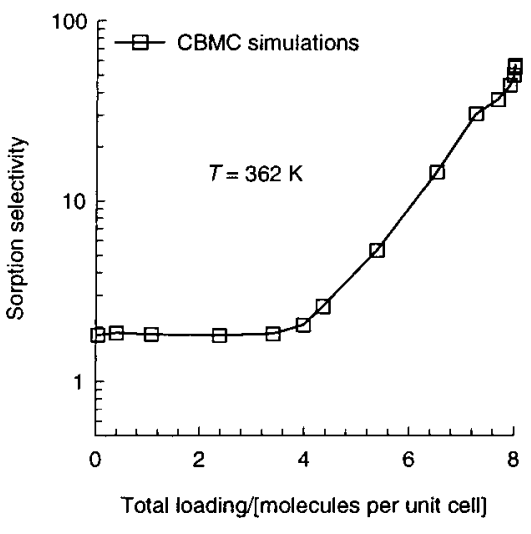

(b) nC6/3MP selectivity at $443 \mathrm{~K}$

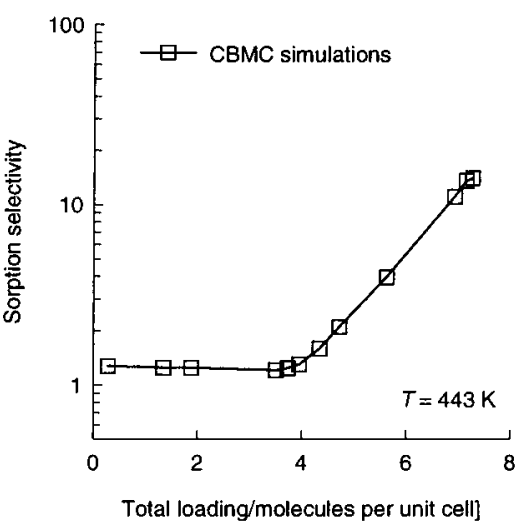

(c) $\mathrm{nC} 6 / 3 \mathrm{MP}$ selectivity at various $T$

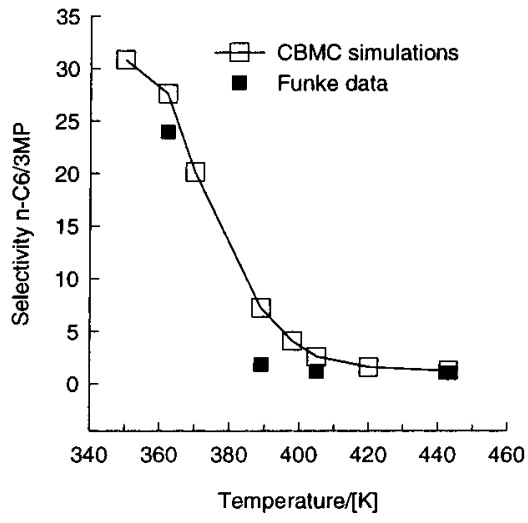

Figure 8. Sorption and permeation selectivities for $50-50$ mixture of $\mathrm{nC} 6-3 \mathrm{MP}$ at 362 and $443 \mathrm{~K}$.

loadings from the pure component isotherms using the ideal adsorbed solution theory (IAST) of Myers and Prausnitz. ${ }^{23}$ Wehavechosen thel AST in view of therecent success obtained with the description of mixtureisotherms of light al kanes in silical ite. ${ }^{11,12}$ Briefly, the basicequation of IAST theory is the anal ogue of Raoult's law for vaporliquid equilibrium, i.e.

$$
P y_{i}=P_{i}^{0}(\pi) x_{i}
$$

where $x_{i}$ is the mole fraction in the adsorbed phase

$$
x_{i}=\frac{\Theta_{i}}{\Theta_{1}+\Theta_{2}}
$$

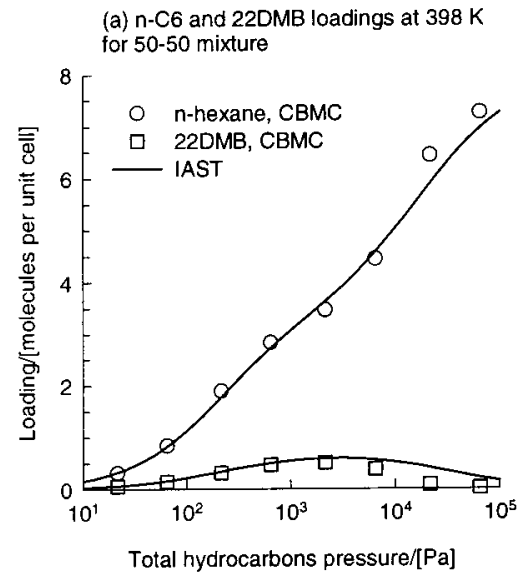

(b) Selectivity at 398 K for 50-50 mixture

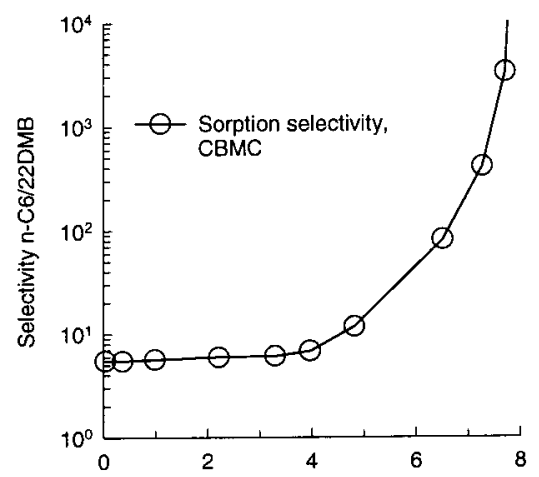

Total mixture loading/[molecules per unit cell]

(c) 22DMB flux and loading at $398 \mathrm{~K}$ for 50-50 mixture

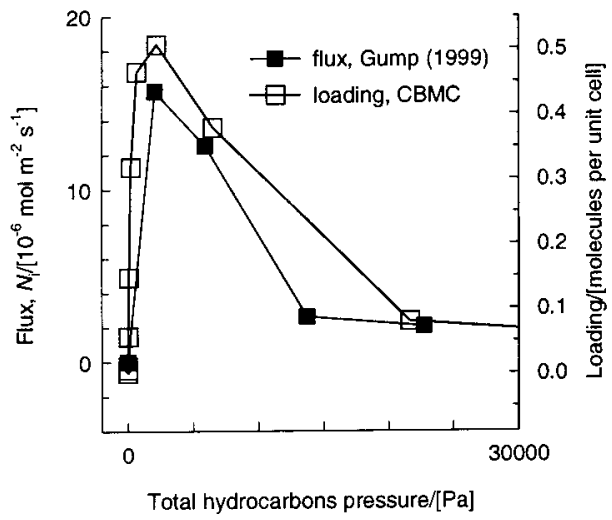

Figure 9. (a) CBMC simulations for 50-50 mixture isotherm for nC6-22DMB at $398 \mathrm{~K}$. (b) Sorption sel ectivity from CBMC simulations. (c) Comparison of loading of 22DMB with fluxes measured by Gump et al. ${ }^{14}$

and $\mathrm{P}_{\mathrm{i}}{ }^{0}(\pi)$ is the pressure for sorption of every pure component $\mathrm{i}$, which yiel ds the same spreading pressure, $\pi$, as that for the mixture. The spreading pressure is defined by the Gibbs adsorption isotherm

$$
\frac{\pi \mathrm{A}}{\mathrm{k}_{\mathrm{B}} \mathrm{T}}=\rho \int_{\mathrm{P}=0}^{\mathrm{P}=\mathrm{P}_{\mathrm{i}}{ }^{0}} \frac{\Theta_{\mathrm{i}}{ }^{0}(\mathrm{P})}{\mathrm{P}} \mathrm{dP}
$$

where $A$ is the surface area $/ \mathrm{m}^{3}$ of adsorbent of the adsorbent, $\mathrm{k}_{\mathrm{B}}$ is the Boltzmann constant, $\rho$ is the density of silicalite expressed in terms of the number of unit cells $/ \mathrm{m}^{3}$, and $\Theta_{\mathrm{i}}{ }^{\circ}(\mathrm{P})$ is the pure component isotherm 
(a) 22DMB flux and loading for $y_{1}=0.2$

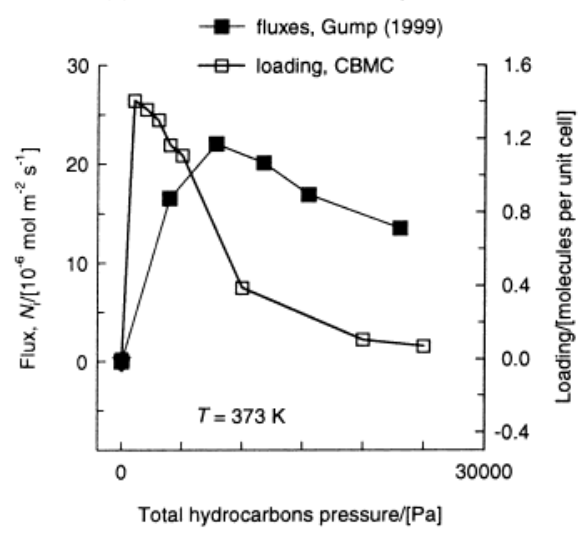

(b) 22DMB flux and loading for $y_{1}=0.3$

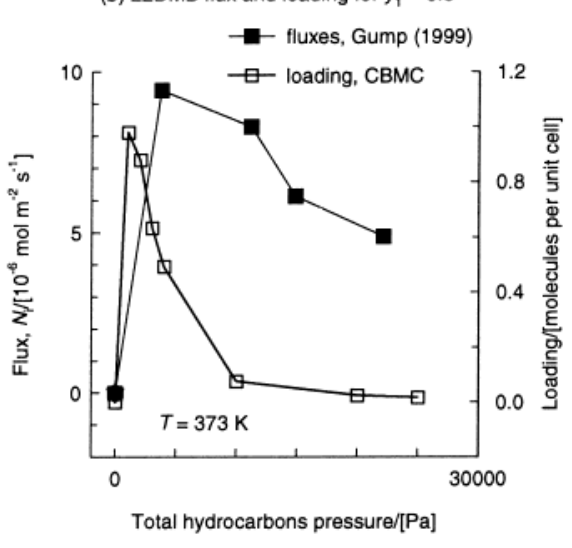

(c) 22DMB flux and loading for $y_{1}=0.4$

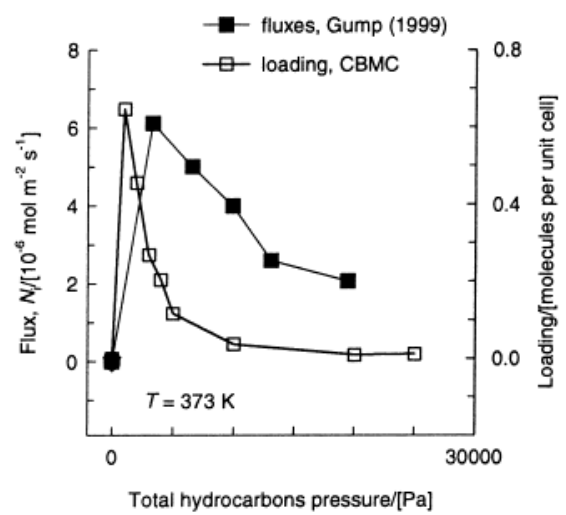

Figure 10. Comparison of CBMC simulations of loading with experimentally determined fluxes of 22DMB for mixtures of nC6-22DMB at $373 \mathrm{~K}$ with various composition vapor phase compositions. Experimental data are from Gump et al. ${ }^{14}$

given by eq 1 . The total amount adsorbed is obtained from

$$
\Theta_{1}+\Theta_{2}=\frac{1}{\frac{x_{1}}{\Theta_{1}^{0}\left(P_{1}^{0}\right)}+\frac{x_{2}}{\Theta_{2}^{0}\left(P_{2}^{0}\right)}}
$$

The set of eqs 1 and $4-7$ need to be solved numerically to obtain the mixture loadings of components 1 and 2 .

We see in Figure $6 a, b$ that the IAST predictions are in reasonably good agreement with the $\mathrm{CBMC}$ mixture loadings. Somedeviations areobserved, especially at high loadings. These deviations are caused by mixture nonideality effects. ${ }^{11}$ (a) Selectivity for $y_{1}=0.2$

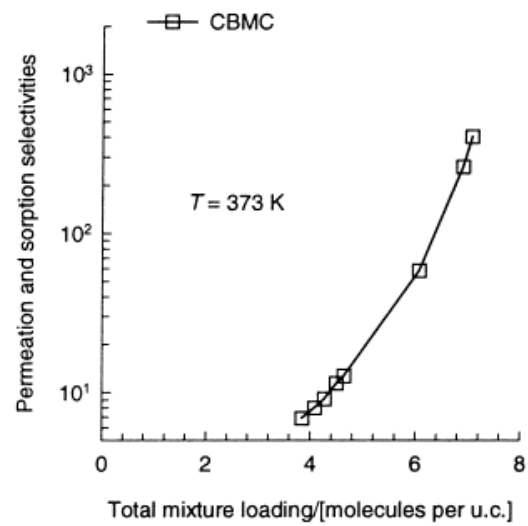

(b) Selectivity for $y_{1}=0.3$

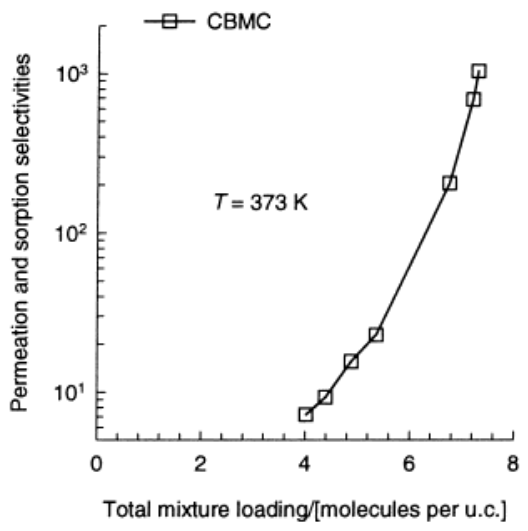

(c) Selectivity for $y_{1}=0.4$

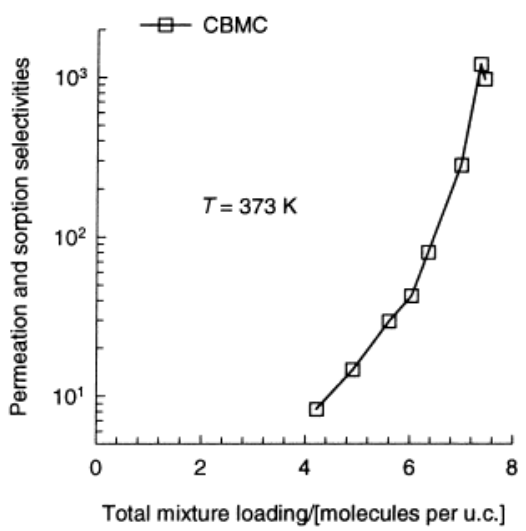

Figure 11. CBMC simulations of sorption selectivity for mixtures of $n C 6-22 D M B$ at $373 \mathrm{~K}$ with various composition vapor phase compositions.

Funke et al. ${ }^{13}$ measured the permeation selectivities for 50-50 mixtures of $\mathrm{nC}_{6}$ and $3 \mathrm{MP}$ at various temperatures, keeping the upstream hydrocarbons pressure at $15 \mathrm{kPa}$; see Table 3 of their paper. What is remarkable is that the permeation selectivity for a $50-50$ mixture $S_{p}$ $=24$ whereas $S_{p}=1.3$ for the pure components. This high mixture selectivity can be explained by examination of Figure $6 \mathrm{a}$, wheretheupstream pressure $(15 \mathrm{kPa})$ condition of the Funke experiment is indicated by a vertical line. The upstream pressure corresponds to a situation well beyond the pressure at which the 3MP loading exhibits a maximum and the sorption selectivity is very high. In another experiment at $443 \mathrm{~K}$, the upstream pressure of 
(a) 50-50 mixture isotherm for $\mathrm{nC5}-2 \mathrm{MB}$

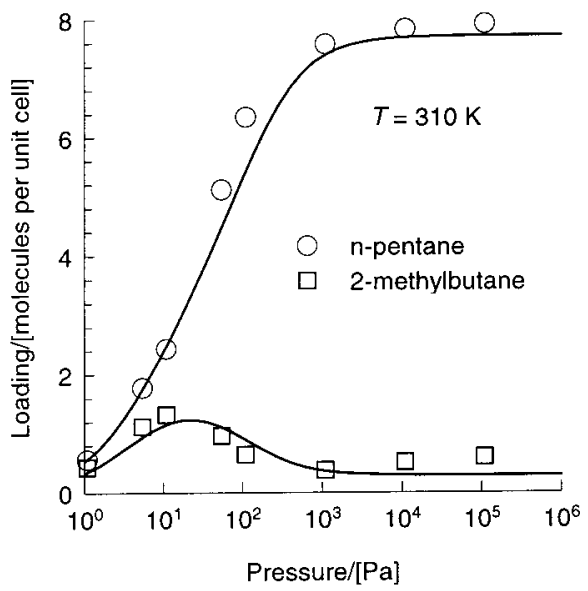

(b) Sorption selectivity for $\mathrm{nC} 5-2 \mathrm{MB}$

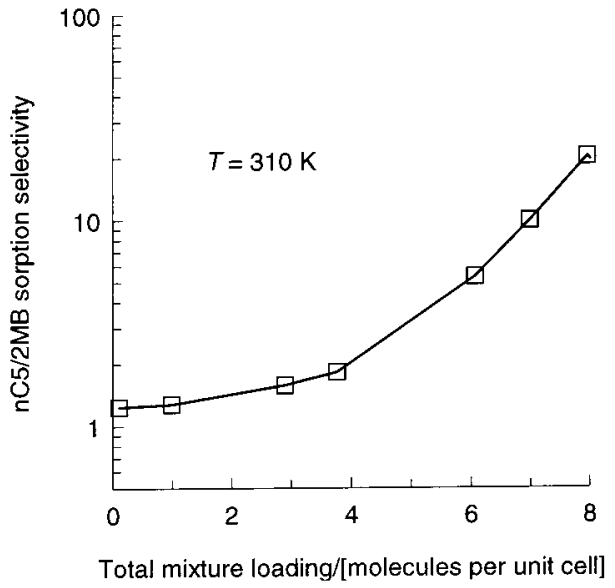

Figure 12. (a) CBMC simulations for 50-50 mixture isotherms for $\mathrm{nC5}-2 \mathrm{MB}$ at $310 \mathrm{~K}$. (b) Sorption selectivity for the mixture.

$15 \mathrm{kPa}$ corresponds closely to the pressure at which the loading of 3MP is at its maximum and therefore the selectivity of $\mathrm{nC}_{6}$ is at its lowest. The CBMC simulations also show that, in order to obtain high selectivities at 443 $\mathrm{K}$, the upstream pressure should be maintained at 1000 $\mathrm{kPa}$. Since, at such high pressures, the hydrocarbon mixture would be in the liquid phase, one technol ogical solution would be to operate in the pervaporation mode (upstream compartment in theliquid phase; downstream compartment in the vapor phase). Matsufuji et al..$^{24}$ have shown that high selectivities for the separati on of hexane isomers can beobtained by operating in thepervaporation mode, underlining these arguments.

From the mixture isotherms presented in Figure $6 a, b$ it becomes clear that configurational entropy effects would manifest only at higher pressures, i.e., at high mixture loadings. Tostress this point, wehavecalculated thesorption selectivity, S, as a function of thetotal mixture loading; the results are presented in Figure 8a,b. The sorption selectivity increases sharply beyond a total loading of 4 molecules/unit cell, corresponding to the situation in which all the intersections are occupied.

Theexperimental permeation selectivities $S_{p}$, measured by Funke et al.,13 are compared with the sorption selectivities $\mathrm{S}$ in Figure $8 \mathrm{c}$ for a range of temperature

(24) Matsufuji, T.; Watanabe, K.; Nishiyama, N.; Egashira, Y.; Matsukata, M.; U eyama, K. Ind. Eng. Chem. Res. 2000, 39, 2434. (a) 50-50 mixture isotherm for $\mathrm{nC} 7-2 \mathrm{MH}$

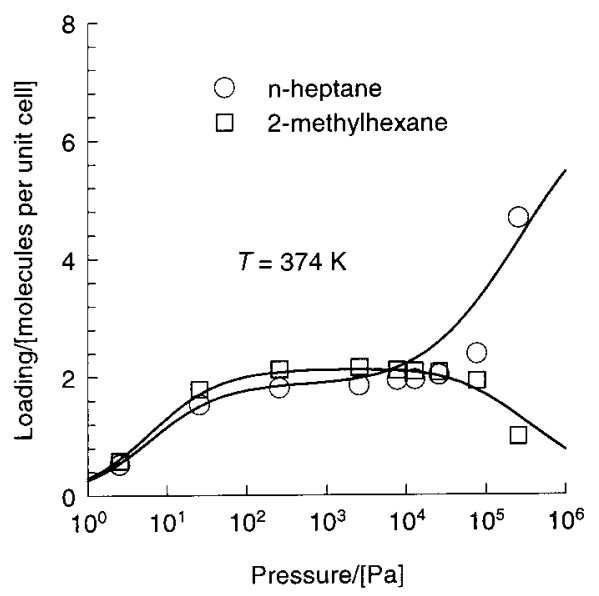

(b) Sorption selectivity for $\mathrm{nC} 7-2 \mathrm{MH}$

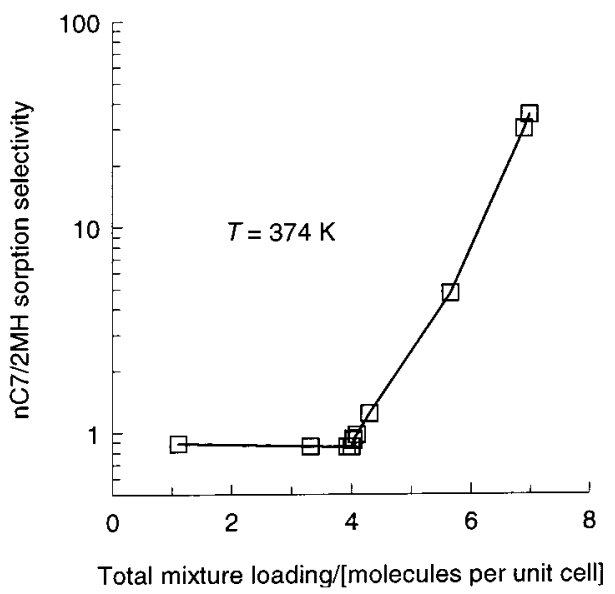

Figure 13. (a) CBMC simulations for 50-50 mixture isotherms for $\mathrm{nC} 7-2 \mathrm{MH}$ at $374 \mathrm{~K}$. (b) Sorption selectivity for the mixture.

conditions keeping the pressure constant at $15 \mathrm{kPa}$. The close agreement between the two sets of results confirm theconfigurational entropy effects arethereasons behind the high sel ectivities observed at lower temperatures. Such effects dimi nish with increasing temperatures, when the pressure is maintained constant at $15 \mathrm{kPa}$.

n-Hexane-2,2-Dimethyl butane Mixtures. CBMC simulations carried out for a 50-50 mixture of (1) $\mathrm{nC}_{6}$ and (2) $22 \mathrm{DMB}$ at $398 \mathrm{~K}$ also show that the double branched is virtual ly excluded at higher pressures due to configurational entropy effects; seeFigure 9 a. FromFigure $9 \mathrm{~b}$ we see that the sorption selectivity increases dramatically beyond a total mixture loading of 4 molecules/unit cell. Gump et al. ${ }^{14}$ have reported the permeation fluxes of 50-50 mixtures of $\mathrm{nC}_{6}$ and 22DMB across a silicalite membrane at $398 \mathrm{~K}$ for various upstream hydrocarbon pressures; see Figures 5 and 6 of their paper. Since the flux of any component is proportional to theloading at the upstream face, we would expect the flux of 22DMB to go through a maximum as the upstream compartment pressure is increased, in steps, from for example 100 to $100 \mathrm{kPa}$. This is precisely what Gump et al. ${ }^{14}$ haveobserved in their experiments. The experimental fluxes of 22DMB are compared in Figure 9c with the 22DMB loadings obtained from CBMC simulations. It is heartening to note that theexperimentally observed maximumflux of 22DMB is obtained at the same pressure at which the 22DMB exhibits a maximum in its loading. 
(a) pure components at $433 \mathrm{~K}$

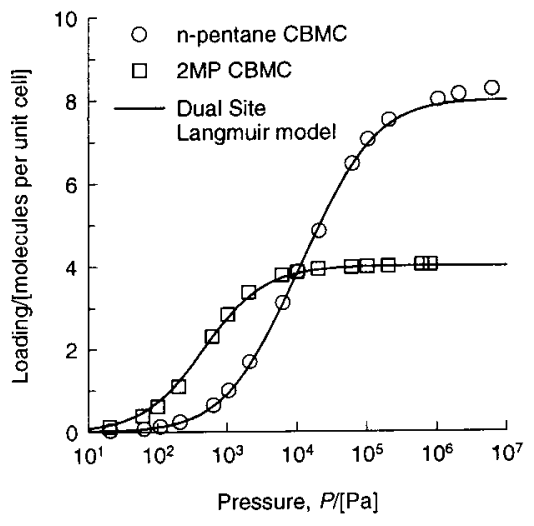

(b) $50-50$ mixture at $433 \mathrm{~K}$

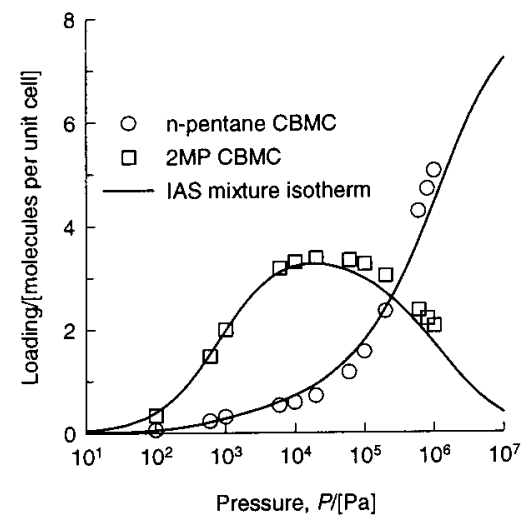

(c) Sorption selectivity in 50-50 mixture

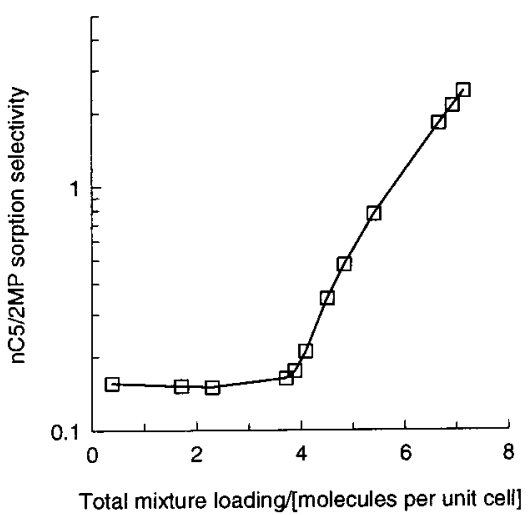

Figure 14. (a) CBMC simulations for pure component isotherms for $\mathrm{nC} 5$ and $2 \mathrm{MP}$ at $433 \mathrm{~K}$. (b) CBMC simulations for 50-50 mixture isotherms for nC5-2MP at $433 \mathrm{~K}$. (c) Sorption selectivity for the 50-50 mixture.

Gump et al..$^{14}$ have also reported the permeation fluxes of mixtures of $\mathrm{nC}_{6}$ and 22DMB across a silicalite membrane at $373 \mathrm{~K}$ for various mixture compositions; see Figures 1 and 2 of their paper. The most intriguing results are the permeation fluxes for 22DMB which show a maximum for a set of vapor compositions $\mathrm{y}_{1}=0.2$, 0.3 , and 0.4 ; see Figure 2 of their paper. To understand these permeation results, the mol ecular loadings of $\mathrm{nC}_{6}$ and 22DMB were determined for the same set of conditions as in the experiments. Our CBMC simulation results for 22DM B loadings are compared with the 22DMB fluxes in Figure 10a-c. For $\mathrm{y}_{1}=0.2,0.3$, and 0.4 the 22DMB loading exhibits a maximum at the same upstream pressure at which theflux maximum is observed. For all threemixtures, thesorption sel ectivities areshown (a) pure components at $433 \mathrm{~K}$

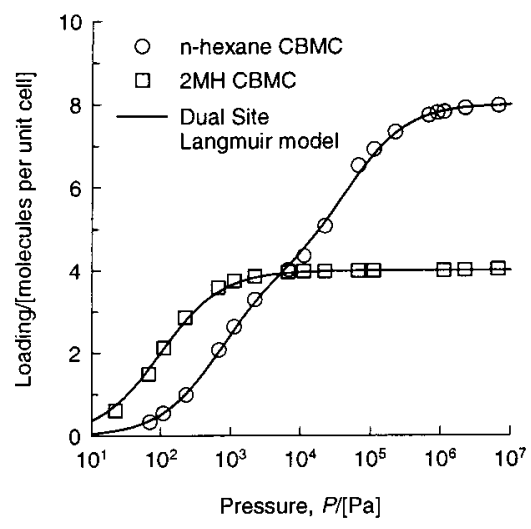

(b) $50-50$ mixture at $433 \mathrm{~K}$

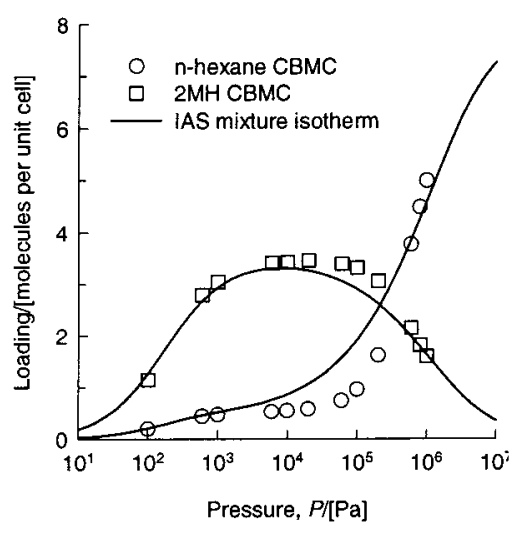

(c) Sorption selectivity of 50-50 mixture

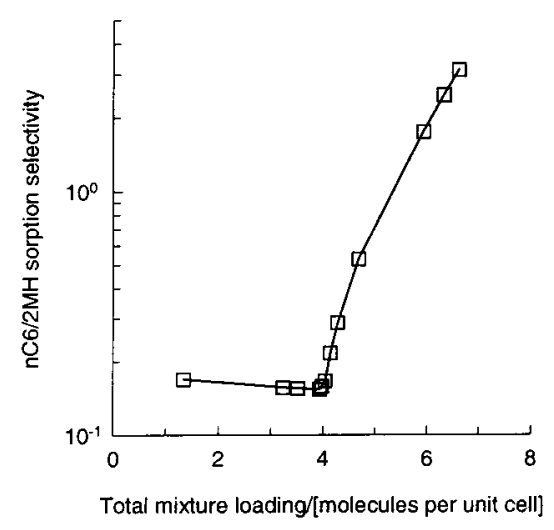

Figure 15. (a) CBMC simulations for pure component isotherms for $\mathrm{nC} 6$ and $2 \mathrm{MH}$ at $433 \mathrm{~K}$. (b) CBMC simulations for $50-50$ mixture isotherms for $\mathrm{nC} 6-2 \mathrm{MH}$ at $433 \mathrm{~K}$. (c) Sorption selectivity for the mixture.

in Figure 11; we see the sharp increase in the selectivity for total mixture loadings in excess of 4 molecules/unit cell.

From theresults presented in Figures 8-10 we confirm that configurational entropy effects cause the exclusion of the branched isomer from the silicalite structure. Our explanation of the membrane permeation experiments is essentially different from that proposed by F unkeet al..$^{13}$ and Gump et al., ${ }^{4}$ who consider then-hexaneto effectively "block"thepermeation of branched isomers. Theseauthors donot offer an explanati on of their membrane permeation experimental results in terms of the entropy effects explained here.

I somers of Pentane and Heptane. Configurational effects also prevail when considering mixture isotherms 


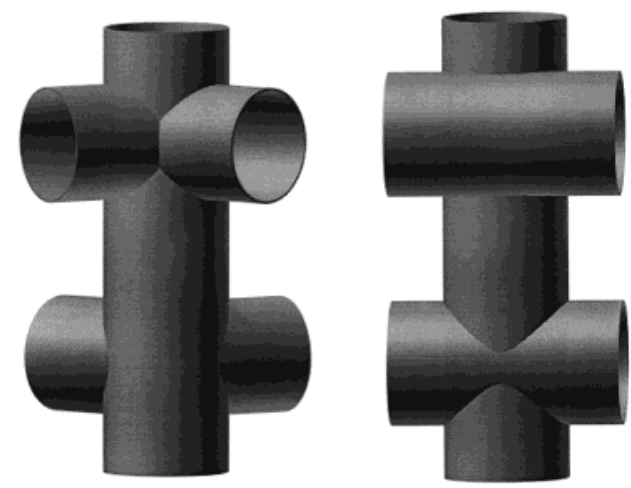

Figure 16. Schematic of silicalite (MFI) and MEL structures, shown respectively on the left and right sides.

of isomers of pentane and heptane. Figure 12a shows 5050 mixture i sotherms for $n$-pentane and 2-methyl butane. The sorption selectivity increases after a mixture loading of 4 molecules/unit cell; see Figure 12b. Figure 13a shows 50-50 mixture isotherms for $\mathrm{n}$-heptane and 2-methylhexane $(2 \mathrm{MH})$, respectively. The curious table mountain loading behavior of $2 \mathrm{MH}$ is notable. Beyond a total mixture loading of 4 molecules/unit cell, the sorption selectivity increases dramatically in favor of the linear isomer. For the $C_{7}$ isomer mixture, reasonably high selectivities are only realized when the operating pressure is higher than e.g. $1000 \mathrm{kPa}$. At such high pressures the mixture is present in the liquid state. So, if membrane permeation is resorted to, then we should operatethe membrane unit in the pervaporation model. ${ }^{24}$ If the isomer separation is to be realized in a packed bed, then the process needs to be operated in the liquid phase. Weal so see from Figures 12 and 13 that the IAST provides a reasonably good description of the mixture isotherms.

n-Pentane-2-Methyl pentaneMixture. Themixtures considered in the foregoing were made up of molecules with the same number of carbon atoms. In practice we also have to deal with mixtures made up of different number of $\mathrm{C}$ atoms. Let us now consider thecharacteristics of a mixture on $\mathrm{nC}_{5}$ and $2 \mathrm{MP}$. The pure component and 50-50 isotherms determined from CBMC simulations are shown respectively in Figure 14a,b. This mixture repre sents an interesting combination because there are two conflicting factors which determine the sorption characteristics of the mixture: (a) chain length effects, which tends to favor 2MP; (b) configurational entropy effects, which tends to favor $\mathrm{nC}_{5}$. Since configurational entropy effects begin to play a rol eonly at high loadings (exceeding 4 molecules/unit cell), we would expect a selectivity reversal at increased loadings. This is indeed found to be thecase; seeFigure 14b,c. Configurational entropy effects overrule chain length effects when the mixture loading increases beyond 4 molecules/unit cell. The IAST again provides a reasonabledescription of the mixturebehavior and reflects the selectivity reversal phenomena adequately.

n-Hexane-2-Methylhexane(2MH) Mixtures. Let us now consi der the characteristics of a mixture of $n$-hexane $\left(\mathrm{nC}_{6}\right)$ and $2 \mathrm{MH}$. Thepurecomponent and $50-50$ isotherms deter mined from CBMC simulations are shown in Figure $15 a, b$. As in the foregoing case the mixture behavior is governed by the conflicting effects of chain length (favoring $2 \mathrm{MH}$ ) and configurational entropy effects (favoring $\mathrm{nC}_{6}$ ). The net result is that we again observe the phenomenon of selectivity reversal; see Figure 15 c. The sharp increase in the sorption selectivity beyond a total mixture loading of 4 molecules/unit cell is noteworthy. We once again find (a) pure component isotherms

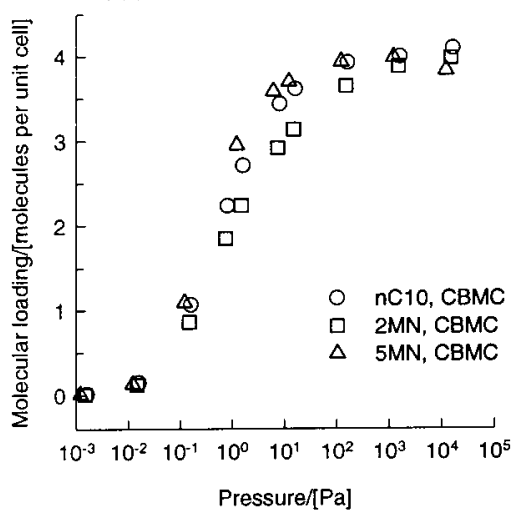

(b) 50-50 mixture isotherm for $\mathrm{nC} 10-2 \mathrm{MN}$

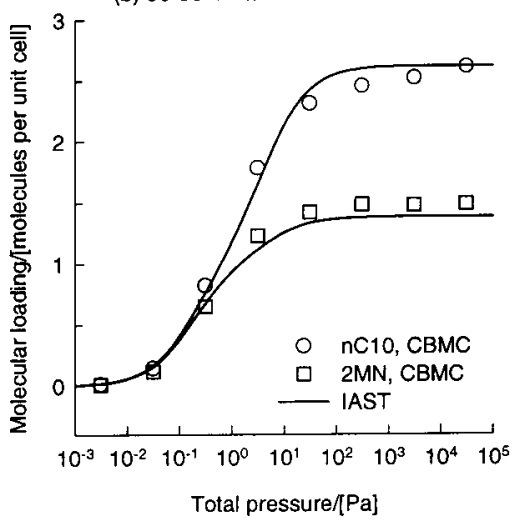

(c) 50-50 mixture isotherm for $\mathrm{nC} 10-5 \mathrm{MN}$

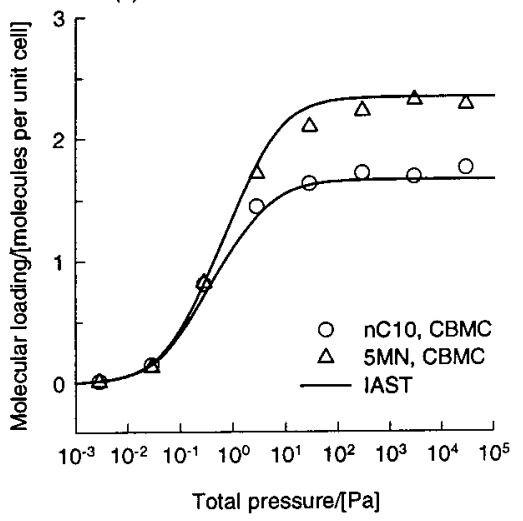

Figure 17. (a) CBMC simulations for pure component isotherms for $\mathrm{nC} 10,2 \mathrm{MN}$, and $5 \mathrm{MN}$ at $415 \mathrm{~K}$ in silicalite. (b) CBMC simulations for 50-50 mixtureisotherms for nC6-2MN at $415 \mathrm{~K}$ in silicalite. (c) CBM C simulations for 50-50 mixture isotherms for $\mathrm{nC} 6-5 \mathrm{MN}$ at $415 \mathrm{~K}$ in silicalite.

that the IAST provides a reasonable description of the mixture behavior and reflects the selectivity reversal phenomena adequately.

\section{Influence of Zeolite Structure}

The discussions in the foregoing were restricted to the separation of alkane isomers using silicalite, or MFI, zeolite. The CBMC simulation strategy is not restricted to this zeolite nor to the variety of molecules considered above. Packing efficiency effects al so manifest themselves when considering other structures and molecules. Weshall illustrate this by consi dering pure component and $50-50$ mixture isotherms for the isomers n-decane (nC10), 2-methylnonane (2MN), and 5-methylnonane (5MN) in two different types of zeolite structures: silicalite (MFI) 
(a) pure component isotherms

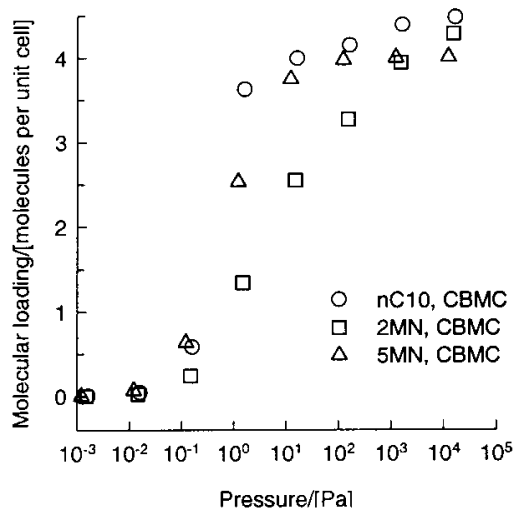

(b) 50-50 mixture isotherm for $\mathrm{nC10}-2 \mathrm{MN}$

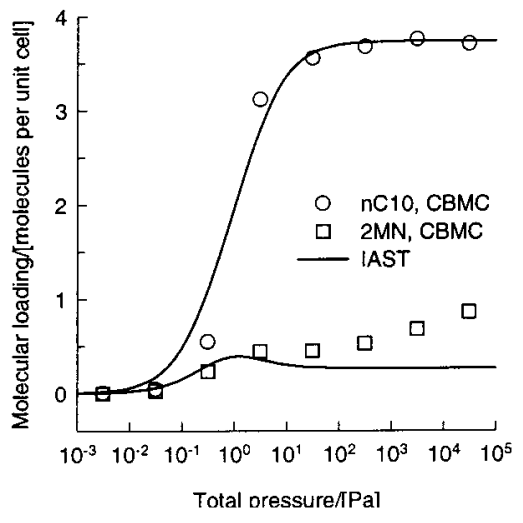

(c) 50-50 mixture isotherm for $\mathrm{nC} 10-5 \mathrm{MN}$

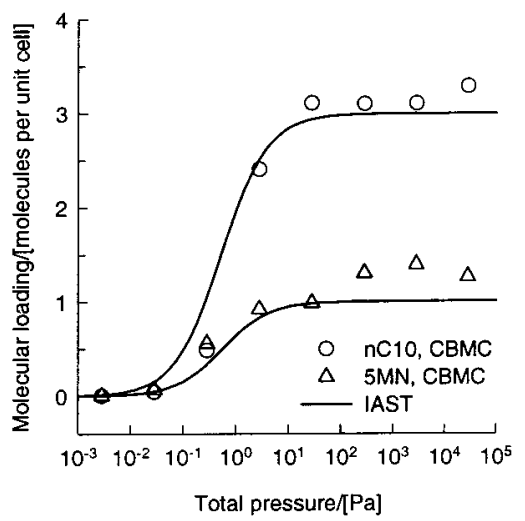

Figure 18. (a) CBMC simulations for pure component isotherms for $\mathrm{nC} 10,2 \mathrm{MN}$, and $5 \mathrm{MN}$ at $415 \mathrm{~K}$ in MEL. (b) CBMC simulations for 50-50 mixture isotherms for $\mathrm{nC} 6-2 \mathrm{MN}$ at 415 $\mathrm{K}$ in MEL. (c) CBMC simulations for 50-50 mixture isotherms for $\mathrm{nC} 6-5 \mathrm{MN}$ at $415 \mathrm{~K}$ in MEL.

and MEL; see Figure 16. Hydroconversion of diesel fractions is important in practice and the distribution of $2 \mathrm{MN}$ and $5 \mathrm{MN}$ in the product fraction obtained from a nC10 feed is often taken as a measure of the performance of a zeol itecatalyst such assilical ite or MEL. Thesezeol ites have a similar pore diameter $(0.55 \mathrm{~nm})$ and structure. Theprincipal differenceis that MFI contains both straight and zigzag channels, while all channels in the MEL structurearestraight. Thereis only onetypeof intersection in the MFI structure. In the MEL structure there are two types of intersections, small or large.

The pure component and 50-50 mixture isotherms at $415 \mathrm{~K}$ in silicaliteare shown in Figure 17. It is interesting to note from Figure $17 \mathrm{~b}$ that, for the 50-50 mixture, the silicalite structure favors thelinear nC10 moleculeto the
Table 2. Pure Component Sorption Parameters for Isomers of Decane for MFI (Silicalite-1) and ME L Zeolites at $\mathbf{4 1 5} \mathrm{K}$

\begin{tabular}{|c|c|c|c|c|c|}
\hline \multirow[b]{3}{*}{$\begin{array}{c}\text { component } \\
\text { i }\end{array}$} & \multirow[b]{3}{*}{ zeolite } & \multicolumn{4}{|c|}{ dual-site Langmuir params (eq 1) } \\
\hline & & \multicolumn{2}{|r|}{ site $A$} & \multicolumn{2}{|r|}{ site B } \\
\hline & & $\begin{array}{l}\mathrm{b}_{\mathrm{i}, \mathrm{A}} / \\
\mathrm{Pa}^{-1}\end{array}$ & $\begin{array}{c}\Theta_{\mathrm{i}, \text { sat,A }} / \\
\text { molecules } \\
\text { per unit cell }\end{array}$ & $\begin{array}{l}\mathrm{b}_{\mathrm{i}, \mathrm{B}} / \\
\mathrm{Pa}^{-1}\end{array}$ & $\begin{array}{c}\Theta_{\mathrm{i}, \text { sat, } \mathrm{B}} / \\
\text { molecules } \\
\text { per unit cell }\end{array}$ \\
\hline \multirow[t]{2}{*}{$\mathrm{nCl0}$} & MFI & 5.8 & 2 & 0.43 & 2 \\
\hline & MEL & 4 & 2 & 2 & 2 \\
\hline \multirow[t]{2}{*}{$2 \mathrm{MN}$} & MFI & 5.8 & 2 & 0.12 & 2 \\
\hline & MEL & 2 & 2 & 0.02 & 2 \\
\hline \multirow[t]{2}{*}{$5 \mathrm{MN}$} & MFI & 5.8 & 2 & 0.85 & 2 \\
\hline & MEL & 1 & 2 & 0.9 & 2 \\
\hline
\end{tabular}

branched 2MN molecule. However, the situation is different when the branching is symmetrically placed at the 5-position; Figure17cshows that the $5 \mathrm{MN}$ molecules have a higher sorption strength in the mixturewith $\mathrm{nC} 10$. This differences in the behavior of the two mixtures is to do with how well thethreemolecules pack insidethesilicalite structure. The 5MN molecule can place its two "legs" in either channel quite comfortably, and this "leg room advantage" hel ps it win the entropic battle with thelinear isomer. Snapshots of the location of $2 \mathrm{MN}$ and $5 \mathrm{MN}$ in silicaliteareavailableon our web site; ${ }^{25}$ theseshow clearly the "leg room advantage" experienced by $5 \mathrm{MN}$.

The situation is different when we consider sorption within MEL structure. TheCBMC data on purecomponent and mixture isotherms are shown in Figure 18. Now, we notethat $\mathrm{nC} 10$ has a higher sorption strength than either $2 \mathrm{MN}$ or $5 \mathrm{MN}$ in the $50-50$ mixtures. Within the MEL structure, 5MN has no "leg room advantage" over the linear molecule. Molecular dynamics simulations of diffusion of these isomers within silicalite and MEL ${ }^{26}$ also show that the diffusivities are significantly affected by the zeolite structure and the position of the branching. Molecular configurations affect both sorption and diffusion.

The differences in the sorption strengths and diffusi vities of decaneisomers in silicaliteand MEL structures could provide an explanation of the striking differences in theproduct distributions obtained during hydrocracking of $n$-decane. ${ }^{26,27}$ Another point to note from the results presented in Figures 17 and 18 is that the IAST mixture rule works reasonably well in the two cases (the pure component fitted data are listed in Table 2).

\section{Concluding Remarks}

We have examined the sorption characteristics of various mixtures of alkanes, in the 5-7 carbon atomrange, in silicalite. The following major conclusions can be drawn: (1) CBMC simulations provide a powerful technique for determining the pure component and mixture isotherms of alkanes. The simulated pure component isotherms arein good agreement with experiment. There are no published experimental mixture isotherms, and therefore, CBMC simulations comeinto their own. (2) F or mixtures of linear and branched alkanes with the same number of carbon atoms, thesorption sel ectivity increases in favor of thelinear isomer for mixtureloadings in excess of 4 molecules/unit cell. This is due to configurational entropy effects. This effect is so strong that the branched alkanes are virtually excluded from the silicalite matrix

(25) http://molsim.chem.uva.nl/MFI_MEL.

(26) Webb, E. B.; Grest, G. S. CataI. Lett. 1998, 56, 95

(27) J acobs, P. A., Martens, J . A.; Weitkamp, J .; Bayer, H. K. Faraday Discuss.Chem. Soc. 1982, 72, 353. 
and high separation factors areachievable. (3) Themixture isotherm characteristics are captured in essence by the IAS theory. (4) A characteristic feature of the configurational entropy effects for alkanes isomers is that, for mixture loadings above 4, the loading of the branched alkanedecreases when thesystem pressure increases. This has implications when a mixture of linear and branched alkanes permeate across a silicalite membrane. At high mixture loadings, the flux of the branched alkane must decrease while the upstream partial pressure increases; this curious behavior has indeed been observed experimentally by Gump et al.. ${ }^{14}$ Their experimental results can be rationalized on the basis of our CBMC mixture simulations. (5) For sorption of mixtures of nC5-2MP and $\mathrm{nC} 6-2 \mathrm{MH}$ within silicalite, chain length and configurational entropy effects counteract each other. At high mixture loadings, configurational entropy effects tend to mask the effect of chain length. Such selectivity reversal effects have never been stressed before in the literature.
In addition tothesimulations for mixtures in silicalite, we have also shown that configurational entropy effects affect the sorption isotherms for isomers of decane; the branched isomer $5 \mathrm{MN}$ wins the entropic battle over $\mathrm{nC} 10$ within silical ite. This is because it has leg-room advantage. CBMC simulations can be helpful in screening zeolite structures for catalytic conversion. ${ }^{28}$

Acknowledgment. All theauthors of this study have received grants from The Netherlands Organization for Scientific Research (NWO), through The Netherlands Research Council for Chemical Sciences (CW) and The Netherlands Technology Foundation (STW). S.L.V. acknowledges support from the ESF scientific program SIMU.

\section{LA001189V}

(28) Maesen, T. L. M.; Schenk, M.; Vlugt, T. J . H.; de J onge, J . P.; Smit, B. J . Catal. 1999, 188, 403. 